\title{
A growth model to predict body weight and body composition of broilers
}

\author{
${ }^{1}$ Galyna Dukhta $-{ }^{2}$ Jaap van Milgen $-{ }^{1}$ György Kövér $-{ }^{1}$ Veronika Halas \\ ${ }^{1}$ Kaposvár University, Kaposvár, Hungary \\ ${ }^{2}$ PEGASE, Agrocampus Ouest, INRA, France \\ galyna.dukhta@ke.hu
}

SUMMARY

\begin{abstract}
Models predicting the nutrient partitioning and animal performance have been developed for decades. Nowadays, growth models are used in practical animal nutrition, and they have particular importance in precision livestock farming. The aim of the present study was to introduce a broiler model and to provide examples on model application. The model predicts protein and fat deposition as well as the body weight of an individual broiler chicken from digestible nutrient intake over time. Feed intake (FI) and the digestible nutrient content of the feed are inputs as well as some animal factors like: initial $\mathrm{BW}$, feed intake at 1 and $2 \mathrm{~kg}$ of $\mathrm{BW}$, precocity and mean protein deposition. The protein and energy metabolism is represented as in the classical nutrient partitioning models. The protein deposition (PD) is driven by digestible amino acid supply and is under "genetic control", the so-called potential PD limits the actual PD if protein is oversupplied.

The authors discuss how the model can be used to simulate the animal response upon different scenarios. Examples are given to show that the diet might be limiting if some animal trait is changed. Applicability of the model has shown through running the model by using different feed strategies (three- vs five-phase-feeding) and variations with animal factors. In conclusion, growth models are useful tools to support decision making for defining the most suitable feeds used in a broiler farm. The model presented in this paper shows a high sensibility and flexibility to test different scenarios. By challenging the model with different inputs, the animal response in terms of changes in body weight and feed conversion can be understood more by studying the shift in deposition of chemical constituents. The examples provided in the present paper shows the benefit of using mathematical models and their applicability in precision nutrition. It can be concluded that the growth model helps to apply "from desired feed to desired food" concept.
\end{abstract}

Keywords: broiler, growth model, protein and fat deposition, feed efficiency.

\section{INTRODUCTION}

In the early ' $60 \mathrm{~s}$, the world produced less than 10 million tons of poultry meat and by 2013 ; this value was more than 96 million tons (FAOSTAT 2017). This increment in production volume is attributed not only to a larger number of slaughtered broilers but a higher body weight at slaughter. On the other hand, evolutionally, meat type chickens reach market in younger age due to intensive selection for commercial objectives. The number of days, total feed and in turn energy required raising a broiler to slaughter weight has decreased dramatically. Genetic improvement in poultry is faster than in other species because poultry breeders have advantages of large population size, short generation interval and considerable genetic variation available to them (McKay 2009). The broiler chicken's growth rate increased by over $400 \%$ between 1950 and 2005 (Zuidhof et al. 2014). Due to the increased growth rate, both the energy intake per day and the metabolic heat production rate have increased, whilst the efficiency of utilising energy for growth has improved (Tallentire et al. 2016). The better energy efficiency comes from improved metabolic efficiency in modern breeds selected on high-quality feed. In result, broilers reach slaughter weight more quickly and therefore need to allocate less energy overall to basal metabolic processes.

Chemical and physical body composition systematically changes during the growth and these changes got into the scientific focus more than ninety years ago (Mitchel et al. 1926). The growth of the body is the sum of changes in chemical constituents.
Chemical components follow a certain pattern as a function of age and based on that there has been number of attempts to predict the growth and body composition of chicken of various genotypes (Hurwitz et al. 1978, Emmans 1981, 1995; Hancock et al. 1995, Hruby et al. 1996, Horn et al. 1998, Sütő et al. 1998, Gous et al. 1999, Markato et al. 2008, Sakomura et al. 2011, Henn et al. 2014, Silva et al. 2014).

As a consequence of the genetic selection the nutrient requirement continuously changes in broilers. Nutrient requirements of broiler breeds in the 1950's have been distinctly lower than nowadays. First recommendation for broilers nutrients supply have been set up by NRC in the 1960's and have been adapted several times, the 1994 edition of NRC being the latest one (NRC 1994). Broiler chickens of any strains have been selected for rapid weight gain and efficient utilization of feed (Havenstein et al. 2003ab). The higher growth rate is attributed to the higher protein deposition rate, thus, the protein and more particularly the essential amino acid requirements increased. This higher demand for amino acids is fulfilled by providing synthetic amino acid supplementation in practical broiler feeds (Grashorn 2017).

There are nutritional tables declaring the energy, amino acid as well as mineral and vitamin requirement of broilers. Most of them, however, do not consider the differences in nutrient requirement of different genetic potential strains. Those recommendations presume an intensively grown broiler with an "ideal" feed intake. In this term, those static recommendations are rather just approximate target values for the feed 
formulation. Each breeder has its own guideline for the nutrient requirement of the strain, but those recommendations are often overestimated the real requirements to simply be on the safe side. It has to be noted, however, that it is difficult to establish a single set of requirements even for a certain strain of broiler because nutrient requirements may vary according to the criterion of adequacy. In the instance of essential amino acids, greater dietary concentrations may be required to optimize efficiency of feed utilization than would be needed to maximize weight gain (NRC 1994). There is also evidence that the dietary requirement for lysine to maximize yields of breast meat of broilers is greater than that needed to maximize weight gain (Acar et al. 1991) and differences exist among strains of broilers with respect to need for more lysine (Bilgili et al. 1992).

There is a general agreement that the nutrient requirement of the animals can be fulfilled more precisely if phase feeding is applied. The recommendations, however, for the time length of different phases are different. Also, it has been confirmed that the more phases are used, the more efficient is the production in terms of using less resources while excreting lower amount of nutrients. Therefore, static table values allow less precise diet formulation and therefore they are not suitable for precision nutrition. In sustainability and profitability terms balancing dietary nutrients for actual feed intake is the prerequisite to support maintenance and growth precisely. This needs definitely a dynamic system approach. By their nature dynamic growth models offer that approach and thus they can be used as a tool to define the optimal feed at any time point or interval of growth phase. By mathematical models the nutrient requirement can be estimated precisely at different circumstances and the broiler production can be optimized, thus models support a more reliable decision making in practical farms.

The aim of the present paper is to introduce a broiler model and to provide examples on model application. The authors discuss how the model can be used to simulate the animal response upon different scenarios.

\section{MODEL DESCRIPTION}

The model predicts protein and fat deposition as well as the body weight of an individual broiler chicken from digestible nutrient intake over time (Dukhta et al. 2017). The model is therefore deterministic and dynamic, and it is considered as a mechanistic model even if some empirical equations are included. The protein and energy metabolism are represented as in the classical nutrient partitioning models (Emmans 1981, de Lange 1995, van Milgen et al. 2008). The flowchart on Figure 1 shows the nutrient flows of the metabolic model. Feed intake (FI) and the digestible nutrient content of the feed are inputs as well as some animal factors like: initial BW, feed intake at 1 and $2 \mathrm{~kg}$ of BW, precocity (indicating the maturity rate), mean protein deposition. The daily protein deposition (PD) derives from the digestible amino acid supply that remains after subtracting the obligatory urinary and faecal endogenous losses. The protein deposition is under "genetic control", the socalled potential PD limits the actual PD if protein is oversupplied.

Figure 1: Nutrient flow of the metabolic model for broiler chicken

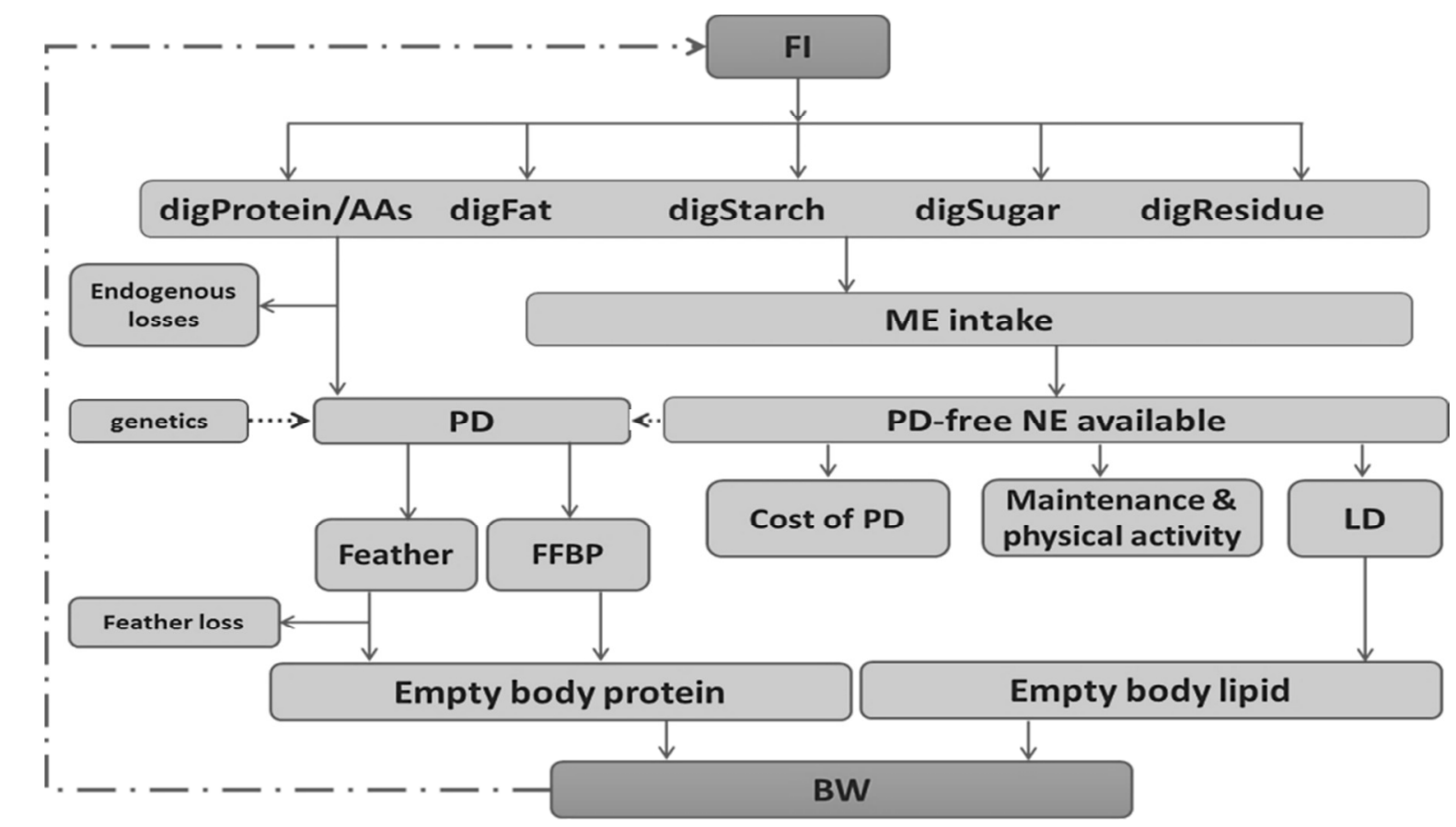

Source: Dukhta et al. (2017) 
Historically, the Gompertz equation has been used to describe the growth of an animal in terms of BW as a function of time. In the broiler model the protein mass at non-limiting condition (considered as its genetic potential) is described by a modified Gompertz function as suggested by van Milgen et al. (2008). The modified Gompertz equation is used to obtain the potential daily PD. By using that approach, protein deposition has a limitation by genetic potential, and became driven by state and not by age, meaning that compensatory PD can occur.

In fact, the sophisticated Gompertz equation for body protein mass is as follows:

$$
P t=P m \cdot \exp [-\exp ((\ln (-\ln (P i / P m))-(\boldsymbol{B} \cdot t)))]
$$

where: $P m=$ prot_final $\cdot(\text { prot_final / prot_init })^{\wedge}(B f /$ $(1-B f))$, duration $=$ age final - age_init, $B f=\exp \cdot(-$ precocity . duration), Prot_final $=$ duration. (meanPD / 1000) + prot_init

and Potential PD = precocity $\cdot$ prot_init $\cdot \ln (P m /$ prot_init)

where: Pt-protein mass at time $t$; Pm-protein mass at maturity; prot_final - protein weight at the end of simulation; prot_init - initial protein weight at hatch; $B$, precocity - maturity rate; age_final - age when maximum growth rate is achieved; age_init - hatching day ( 0 day); $B f$ - fractional rate of growth, mean $P D-$ the mean protein deposition in the simulated period. MeanPD value closely related to average daily gain, interacting with precocity gives a specific meaning to growth function and determines the early or late maturing of the animal.

The daily protein deposition in the model is divided between feather protein development and feather free empty body protein deposition. The first one is determined by a classical Gompertz function described by Emmans (1981) and considered as an obligatory flow. The feather loss is also taken into account in the model as a part of maintenance needs.

Digestible nutrients provide the metabolizable energy for the bird and the efficiency of energy yielded from different nutrients are taken into account. Factors for energy conversion of digestible nutrients to metabolizable and net energy are presented in Table 1. The values were determined by Carré et al. (2014). In the model the energy is used for maintenance and it supports the energy needed for the actual PD, protein turnover as well as physical activity, and the rest is converted to body lipid.

The amount of water and ash in the body is assumed to be proportional with the body protein mass. Ash in empty body weight is presumed to be $20 \%$ of the empty body protein, while the water mass is described by allometric function of empty body protein.
Table 1

Energy conversion factors used in the broiler model (kJ/g, according to Carré et al. 2014)

\begin{tabular}{lccc}
\hline & Coef ME & Coef AMEn & Coef NE \\
\hline Crude fat & 38.38 & 37.77 & 32.43 \\
Crude protein & 20.60 & 18.36 & 14.32 \\
Starch & 17.00 & 16.67 & 13.28 \\
Sugars & 13.02 & 12.52 & 7.932 \\
Residue & 9.93 & 9.30 & 12.710 \\
\hline
\end{tabular}

As it is shown in Figure 1, the feed intake is driven by body weight. The equation that is used for the estimation of the daily feed intake is based on the premise that the birds eats for their energy requirement. The so-called Gamma-function is a transposed exponential equation that shows the net energy intake (NEI) capacity of the bird as a function of maintenance. The approach was adapted and the equation was re-parametrised from the pig model InraPorc (van Milgen et al. 2008).

$$
N E I(M J / d)=(a \cdot b \cdot B W \cdot \exp (-b \cdot B W)+1) \cdot c \cdot B W^{d}
$$

where: $a$ and $b$ are coefficients calculated from FI at 1 and $2 \mathrm{~kg}$ of $\mathrm{BW} ; c=0.8-$ coefficient related to maintenance (Carré et al. 2014); d = 0.7 - power for metabolic body weight (Noblet et al. 2015).

It has been proven that the model predicts the ideal trajectory of feed intake with high precision in optimal environmental and health conditions (Dukhta et al. 2017).

As it was mentioned the model has feed related parameters and certain animal traits as inputs. The animal is characterised by initial body weight, precocity as an indicator of the shape of protein growth, as well as by mean PD. This parameterisation is convenient for model users as the parameters have a biological and practical meaning (Figure 2). The higher precocity value results in an early-maturing animal, and the low precocity reflects to a latematuring animal. By changing precocity value, the mature body weight is not changing seriously. The meanPD certainly determines the maximum protein deposition and, thus, this is the main driving force for the potential body weight at any time step. There is considerable difference in the shape of growth between males and females. Males are heavier and leaner than females, and the difference between sexes appears from approximately 3 weeks of age (Horn et al. 1998). Literature data for precocity of protein deposition in broilers vary between 0.038 to 0.056 among different strains and sexes, while the mean PD for a 42 day growing appear between 9 and $14 \mathrm{~g} /$ day (Hancock et al. 1995, Gous et al. 1999, Marcato et al. 2008, Henn et al. 2014, Silva et al. 2014, Gonçalves and Sakomura 2017). 
Figure 2: Predicted body weight (BW) at fixed mean PD (11 g/d) and different precocity parameters (left) and at fixed precocity (0.040) and different mean PD (right)

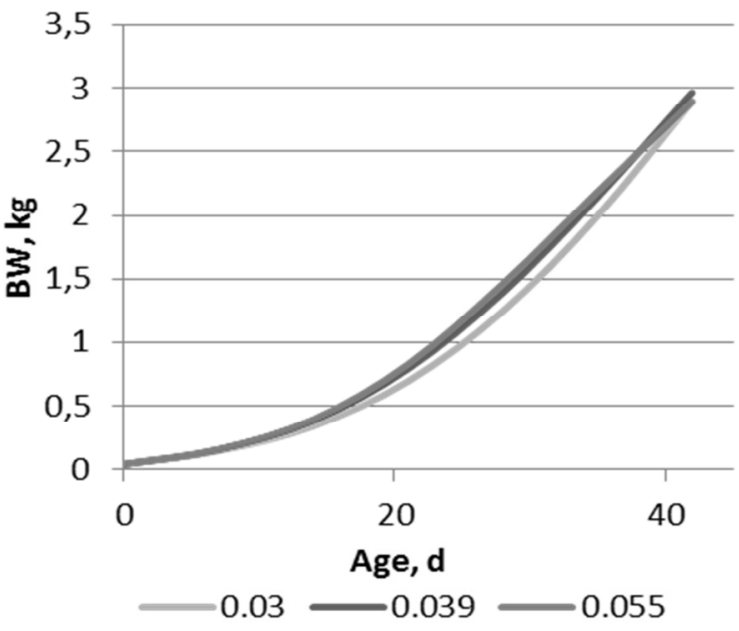

\section{APPLICATION OF THE BROILER MODEL}

The model is available to test different scenarios and therefore it helps to make decision according to the simulation results. In the following case studies, the model is challenged with different inputs studying the effect of individual animal traits such as precocity and mean PD (case study 1) as well as with different feeding strategies (case study 2). In case study 3 the same diets and feeding regime is used and the

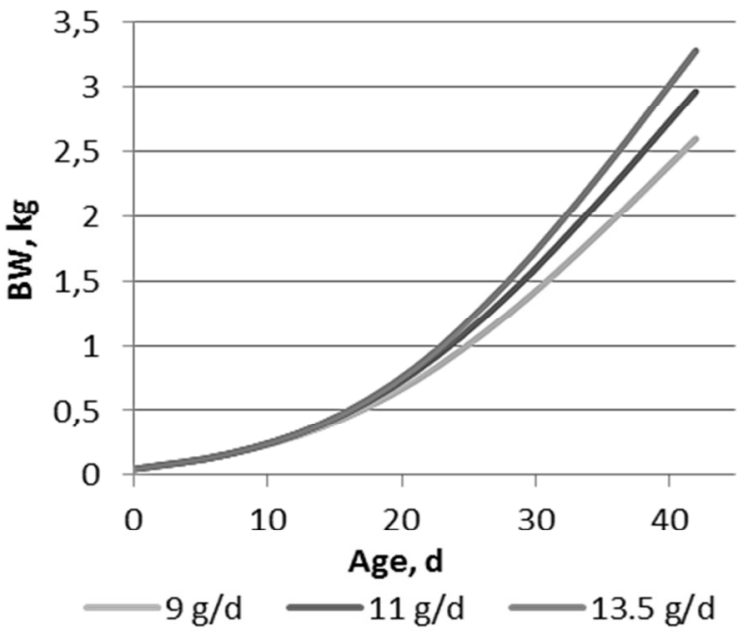

performance (BW and chemical body composition) of two different characteristics animals are simulated.

In simulations the model was run with diets as shown in Table 2 and the initial conditions of animal traits were the same in both simulations: initial $\mathrm{BW}=$ $44 \mathrm{~g}$; FI at $1 \mathrm{~kg} \mathrm{BW}-1.2$ and at $2 \mathrm{~kg} \mathrm{BW}-1.9 \mathrm{~kg}$; precocity: $0.040 ;$ meanPD $=11 \mathrm{~g} / \mathrm{d}$; duration is 42 days.

Nutritional composition of the diets in model simulations

\begin{tabular}{lcccccccc}
\hline & \multicolumn{3}{c}{3 phases feeding } & \multicolumn{4}{c}{5 phases feeding } \\
\cline { 2 - 8 } & $0-14 \mathrm{~d}$ & $15-28 \mathrm{~d}$ & $29-42 \mathrm{~d}$ & $0-10 \mathrm{~d}$ & $11-20 \mathrm{~d}$ & $21-28 \mathrm{~d}$ & $29-35 \mathrm{~d}$ & $36-42 \mathrm{~d}$ \\
\hline AMEn & 13.00 & 13.00 & 13.00 & 13.00 & 12.99 & 12.84 & 12.56 \\
CP & 24 & 22 & 19 & 24 & 22 & 21 & 12.36 \\
dig Lys & 1.56 & 1.33 & 1.14 & 1.56 & 1.33 & 1.14 & 1.18 & 19 \\
dig Met & 0.55 & 0.47 & 0.40 & 0.55 & 0.47 & 0.40 & 0.42 \\
dig Thr & 0.90 & 0.80 & 0.71 & 0.90 & 0.80 & 0.75 & 0.72 & 0.71 \\
\hline
\end{tabular}

In case study 1 dietary inputs of nutrient content of three-phase reference diets was taken from literature (Gonçalves and Sakomura 2017). It has been discussed that precocity reflects to the dynamics of protein deposition. The first simulation shows the broiler response in terms of protein and lipid deposition if nothing else but the precocity is different (Figure 3). The output of the simulation stresses that by changing the precocity value the diet can be limiting for the birds. In case of a higher precocity, when the animal is early-maturing, and thus it has more intensive growth at the early ages, the starter diet as used in the present simulation is not sufficient to supply enough amino acid for a high genetic potential.
The simulated results suggest that either the feed intake or rather the amino acid supply should be increased by supplementing the diet with amino acids or enhance the digestibility of the protein. However, the model also shows that the better amino acid supply is applicable only in the first 18 days but not later. The figure emphasizes that the fat deposition and consequently the fat content of the body is higher at the slaughter age if the bird is early-maturing. However, due to the fact that the fat deposition is a "sink of the energy", by reducing the dietary energy content of the finisher feed the body fatness can be reduced. 
Figure 3: Predicted daily protein and lipid deposition with three-phase-feeding when meanPD is set as $11 \mathrm{~g} / \mathrm{d}$ and precocity is 0.040 and 0.050 shown on the left and ride sides, respectively

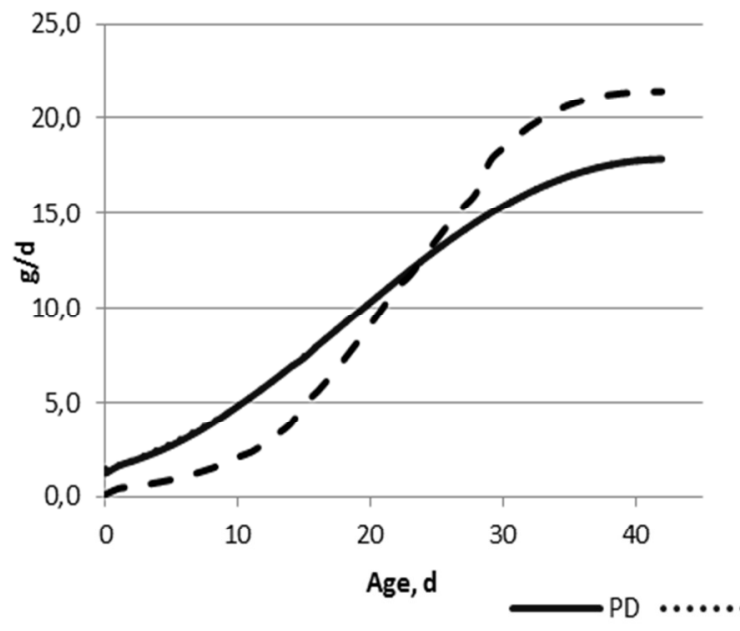

Figure 4 shows the model output if the precocity value is fixed (0.04) and the meanPD is changed from 9 to $14 \mathrm{~g} / \mathrm{d}$. The feeding regime is the same as in the earlier simulation (three-phase-feeding). Based on comparison of the scenarios it can be concluded that the diet was limiting for the birds having a higher meanPD throughout the growing and finishing periods. It is also clearly seen that the protein (and amino acids) was oversupplied in case of low meanPD birds. The actual PD that is allowed by the diet is

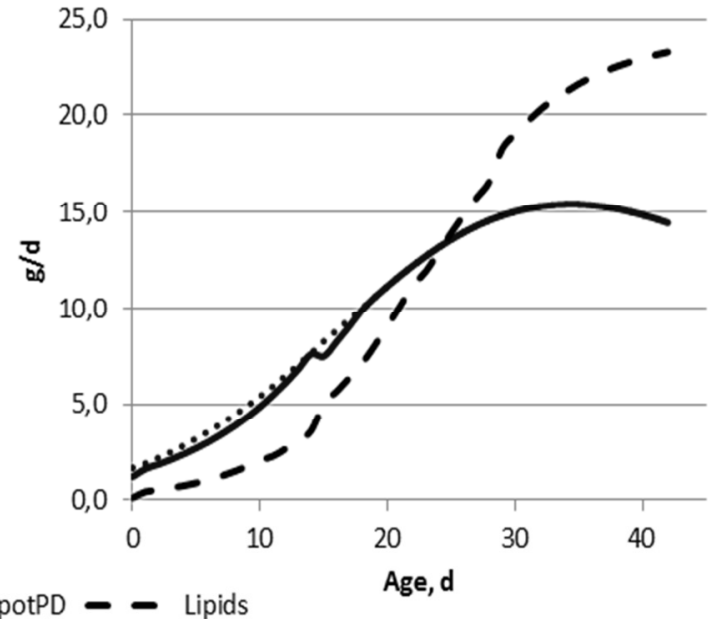

much higher in the right figure, indicating that the genetic potential limited the protein deposition in the left figure. The low meanPD attributed with a higher fat deposition coming from unused dietary protein. The protein deposition requires considerable amount of energy and, thus, in high genetic potential birds (higher mean PD) the energy remained for lipid deposition was much less compared to the low genetic potential counter pair.

Figure 4: Predicted daily protein and lipid deposition with three-phase-feeding when precocity parameter is fixed (0.040) and meanPD is different being 9 and $14 \mathrm{~g} / \mathrm{d}$ on the left and right sides, respectively

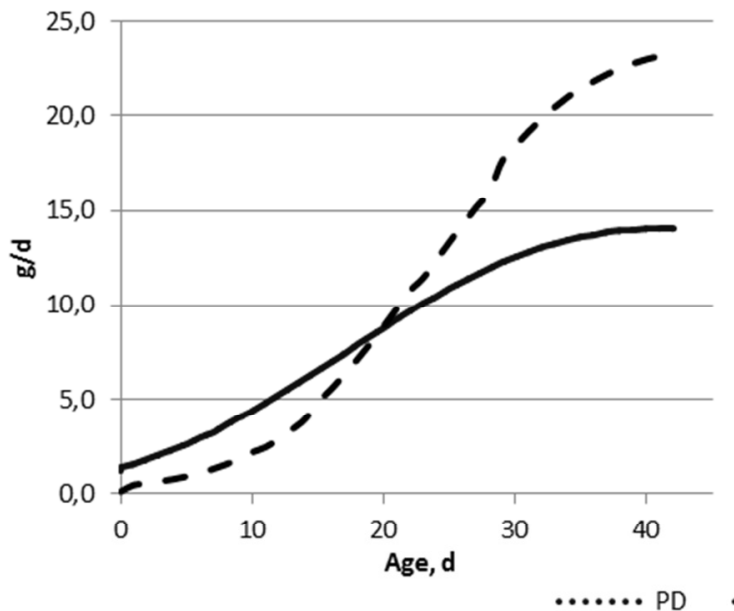

In case study 2 different feeding regimes were compared. The model is challenged with a classical 3phase-and with a 5-phase-feeding regimes (Table 2). The animal traits were kept the same in both simulations as defined above in this paper. The results of the simulations are shown in Figure 5 and 6 . It can be concluded from the PD curves, that PD is limited

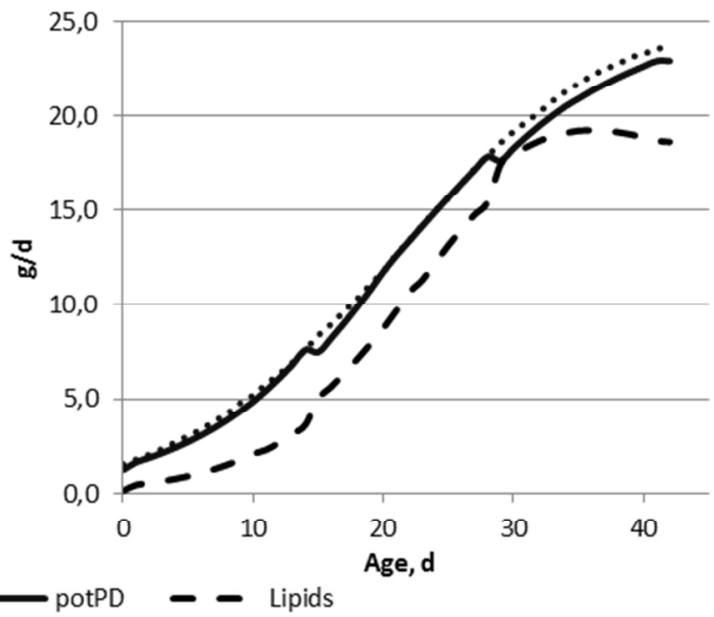

by the diet in some periods if three-phase-feeding was applied, and therefore, fat deposition became a more , noisy' curve. However, there is no major difference in protein and lipid deposition rates. The more phases are usually attributed to the better feed conversion, if not just the number of periods is increased, but the nutrient supply is also adjusted. 
Figure 5: Predicted daily protein and lipid deposition with three-phase-feeding (left) and five-phase-feeding (right) when precocity parameter is fixed $(0.040)$ and meanPD is $11 \mathrm{~g} / \mathrm{d}$

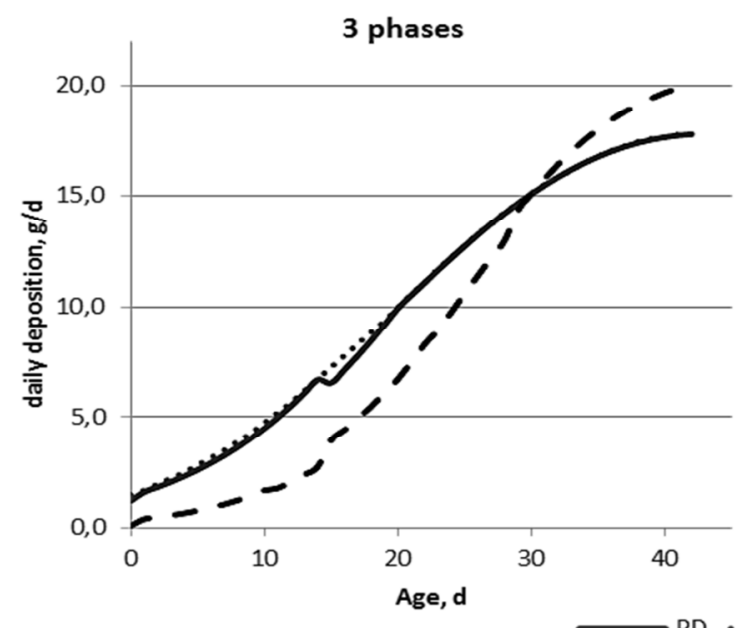

This finding can be confirmed in our simulation, too. Figure 6 (left graphs) shows that feed was more efficiently used if 5 phases were applied. The feed conversion ratio (feed/gain) was higher at the first 20 days if 3-phase-feeding was used. A slight difference in PD at the beginning of first two phases (see Figure 5 left) caused some shift in feed conversion rate. Feed conversion is the efficiency of the diet and it reflects

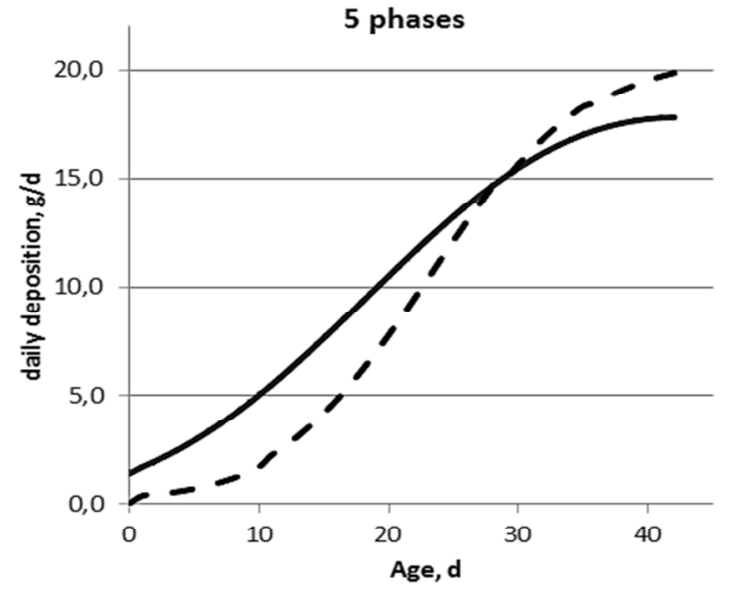

potPD - - Lipids

Figure 6: Comparison of predicted FCR and BW with different phase feeding

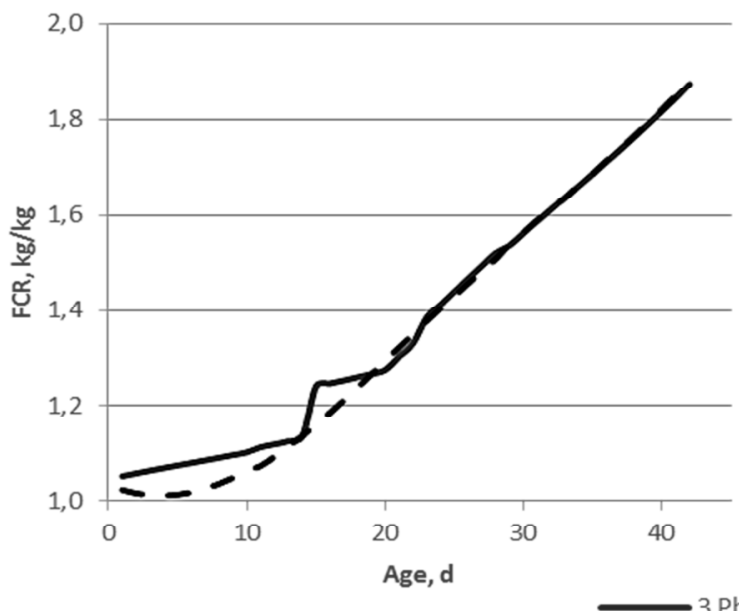

3 Phases on the economic cost of the production. Any difference in slaughter weight has also impact on the profitability of the meat production. The graphs of Figure 6 (right) show that at 35 day of age there is $5 \%$ $(\sim 110 \mathrm{~g})$ difference in BW. With more feeding phases the nutrient requirement was more precisely supplied, and it resulted in higher body weight at 5-phasefeeding simulation.
As it was shown, the higher the body PD is, the higher the BW gains is and the better the feed conversion ratio is. Difference in BW is usually attributed to the difference in deposition of chemical constituents. In case study 3 two different growth characteristics birds' response is simulated. Fivephases-feeding regime defined in Table 2 and two sets of initial input parameters were used: initial BW (44 g) and duration (42 days) were the same, when FI at 1 and at $2 \mathrm{~kg}$ of $\mathrm{BW}$ were $1.2-1.8$ and $1.3-2 \mathrm{~kg}$; precocity 0.040 and 0.055 ; meanPD 11 and $9 \mathrm{~g} / \mathrm{d}$, respectively for the two simulations. The two different

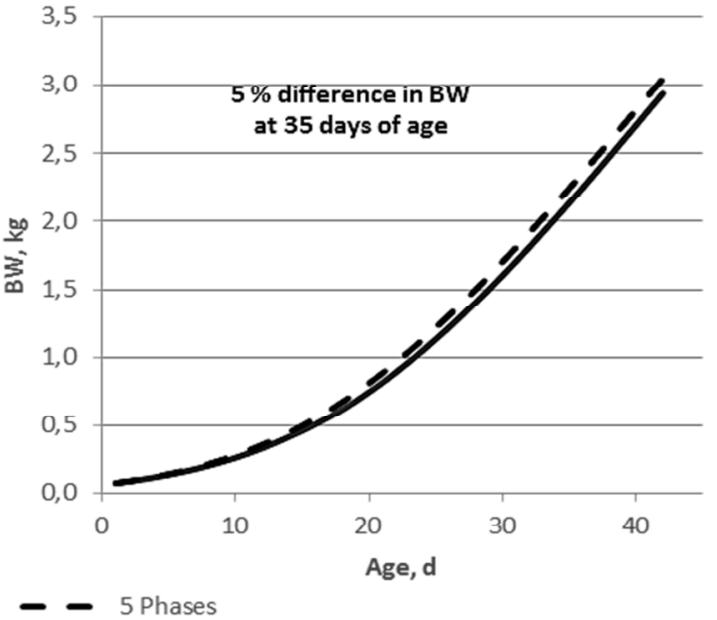

genetic potential animals may represent the two sexes. Males have lower precocity and higher meanPD than females.

Figure 7 shows the output of the simulation on $\mathrm{BW}$ and protein and lipid mass. BW on the left graph is almost $3 \mathrm{~kg}$ at 42 days of age, empty body protein mass is more than $0.5 \mathrm{~kg}$ and empty body lipid is less than $0.4 \mathrm{~kg}$. Those values are realistic for a modern male hybrid, such as our simulation for a female: 2.7 $\mathrm{kg} \mathrm{BW}$ at 42 days of age, $0.45 \mathrm{~kg}$ of protein and almost $0.5 \mathrm{~kg}$ of empty body fat (Gonçalves and Sakomura 2017). The difference in chemical body 
composition of males and females is also confirmed by the simulation. Model prediction in Figure 8 show that bird on the left is much leaner, comparing to the right one, which corresponds to the sex differences (Hancock et al. 1995, Horn et al. 1998, Sütő et al. 1998, Gous et al. 1999).

Figure 7: Predicted BW, cumulative body protein and body lipid with five-phases-feeding and two sets of parameters
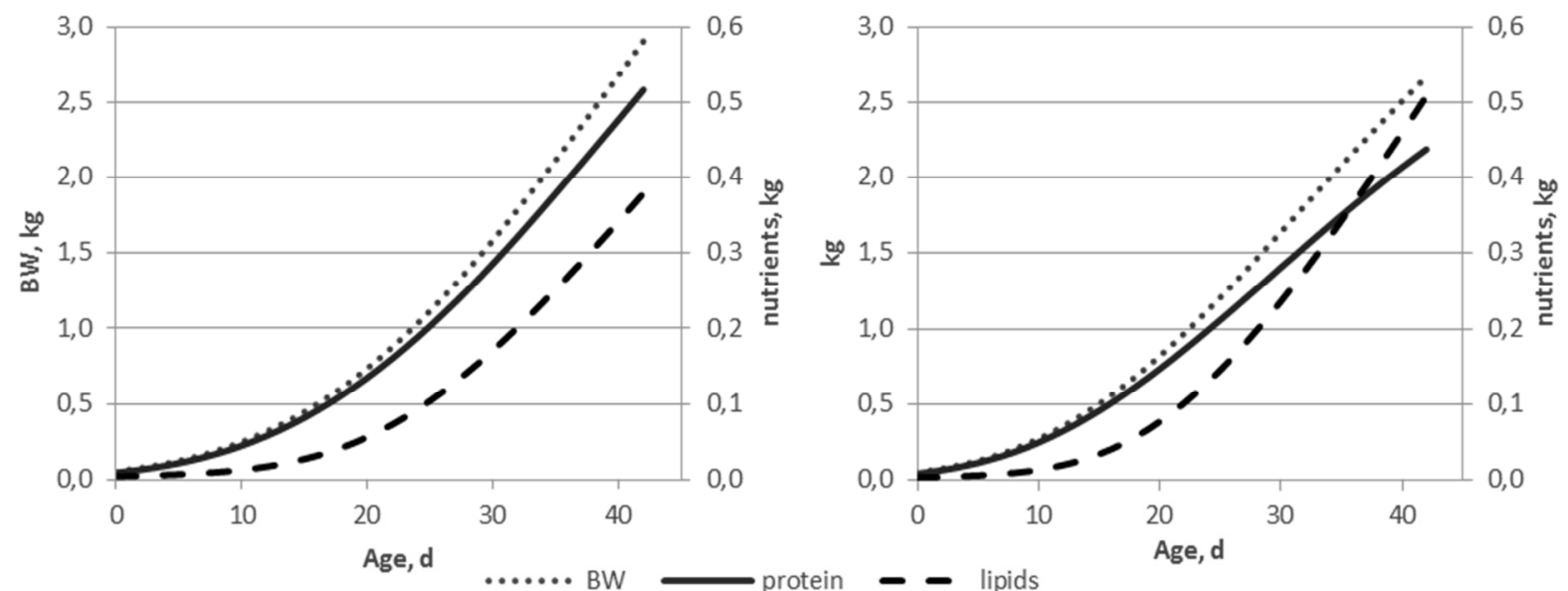

Figure 8: Predicted body compositions simulated with five-phases-feeding and two sets of parameters

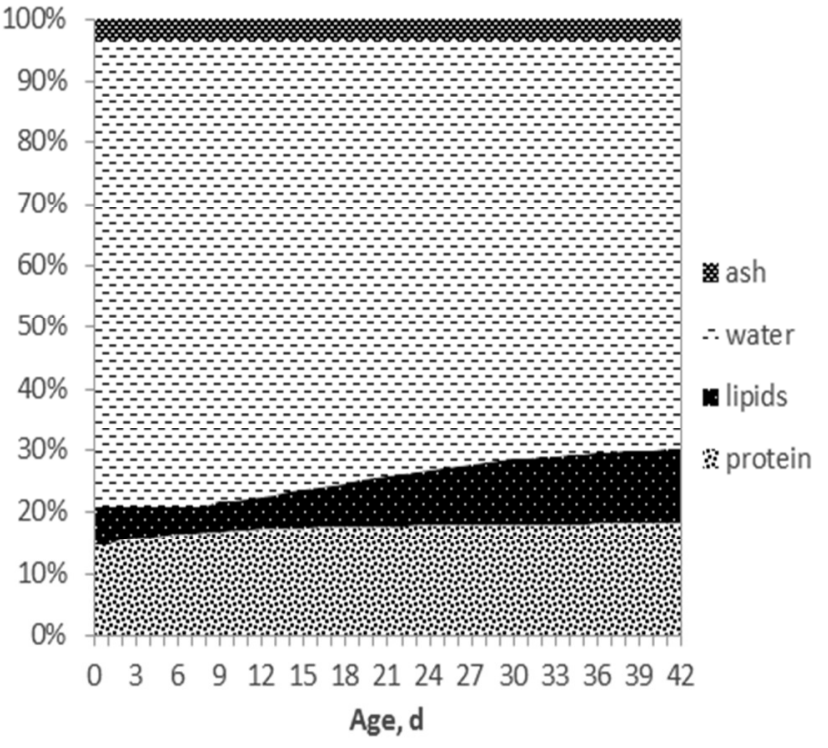

Input parameters I (Figures 7-8, left):

FI at $1 \mathrm{~kg} \mathrm{BW}-1.2 ; 2 \mathrm{~kg} \mathrm{BW}-1.8 \mathrm{~kg}$ precocity: 0.040 ; meanPD $=11 \mathrm{~g} / \mathrm{d}$; initial $\mathrm{BW}=44 \mathrm{~g}$; duration: $42 \mathrm{~d}$

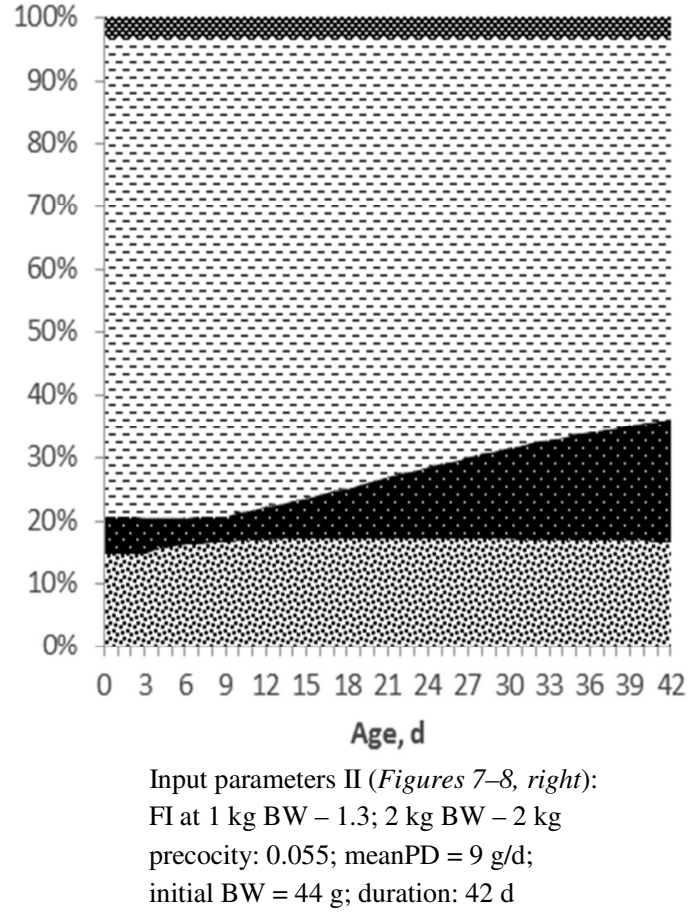

more by studying the shift in deposition of chemical constituents. The examples provided in the present paper shows the benefit of using mathematical models and their applicability in precision nutrition. It can be concluded that the growth model helps to apply "from desired feed to desired food" concept. 


\section{ACKNOWLEGMENT}

This project has received funding from the European Union's Horizon 2020 research and innovation programme under grant agreement No
633531. The publication is supported by the EFOP3.6.3-VEKOP-16-2017-00008 project. The project is co-financed by the European Union and the European Social Fund.

\section{REFERENCES}

Acar, N.-Moran, Jr E. T .-Bilgili, S. F. (1991): Live performance and carcass yield of male broilers from two commercial strain crosses receiving rations containing lysine below and above the established requirement between six and eight weeks of age Poultry Science. 70. 11: 2315-2321.

Bilgili, S. F.-Moran, Jr E. T.-Acar, N. (1992): Strain-cross response of heavy male broilers to dietary lysine in the finisher feed: Live performance and further-processing yields. Poultry Science. 71. 5: 850-858.

de Lange, C. F. M. (1995): Framework for a simplified model to demonstrate principles of nutrient partitioning for growth in the pig. [In: Mougham P. J. et al. (eds.) Modelling growth in the pig.] Wageningen Pers. Wageningen. Netherlands. 71-85.

Dukhta, G.-van Milgen, J.-Kövér, G.-Halas, V. (2017): Reparametrization of a swine model to predict growth performance of broilers. Book of Abstract of the $68^{\text {th }}$ Annua Meeting of the European Federation of Animal. Wageningen. Netherlands. Wageningen Academic Publishers. 320.

Emmans, G. C. (1981): A model of the growth and feed intake of ad libitum fed animals, particularly poultry. [In: Hiller G. M. et al. Computers in animal production. British Society of Animal production, occasional publication. $5^{\text {th }}$ edition.] 103-110.

Emmans, G. C. (1995): Problems in modelling the growth of poultry. World's Poultry Science Journal. 51. 1: 77-89.

FAOSTAT (2017): http://www.fao.org/faostat/en/\#compare (accessed November 2017)

Gonçalves, C. A.-Sakomura, N. K. (2017, Unpublished): Modelagem do crescimento, composição, do corpo e das penas em frangos de corte. Jaboticabal-São Paulo-Brasil.

Gous, R. M.-Moran, Jr E. T.-Stilborn, H. R.-Bradford, G. D.Emmans, G. C. (1999): Evaluation of the parameters needed to describe the overall growth, the chemical growth, and the growth of feathers and breast muscles of broilers. Poultry Science. 78. 6: 812-821.

Grashorn, M. A. (2017): Nutritional requirements of broilers with different growth capacity. Book of Abstracts of the 21st European Symposium on Poultry Nutrition - ESPN 2017 Wageningen. Netherlands. Wageningen Academic Publishers. 102.

Hancock, C. E.-Bradford, G. D.-Emmans, G. C.-Gous, R. M. (1995): The evaluation of the growth parameters of six strains of commercial broiler chickens. British Poultry Science. 36. 2: 247-264.

Havenstein, G. B.-Ferket, P. R.-Qureshi, M. A. (2003a): Carcass composition and yield of 1957 versus 2001 broilers when fed representative 1957 and 2001 broiler diets. Poultry Science. 82. 10: 1509-1518.

Havenstein, G. B.-Ferket, P. R.-Qureshi, M. A. (2003b): Growth, livability, and feed conversion of 1957 versus 2001 broilers when fed representative 1957 and 2001 broiler diets. Poultry Science. 82. 10: 1500-1508.
Henn, J. D.-Bockor, L.-Ribeiro, A. M. L.-Coldebella, A.-Kessler, A. D. M. (2014): Growth and deposition of body components of intermediate and high performance broilers. Revista Brasileira de Ciência Avícola. 16. 3: 319-328.

Horn, P.-Sütő, Z.-Jensen, J. F.-Sørensen, P. (1998): Growth, feed conversion and mortality of commercial meat type chicken during a twenty week growing period. Archiv fuer Gefluegelkunde. 62. 1: 16-20.

Hruby, M.-Hamre, M. L.-Coon, C. N. (1996): Non-Linear and Linear Function in Body Protein Growth. Journal of Applied Poultry Research. 5. 2: 109-115.

Hurwitz, S.-Sklan, D.-Bartov, I. (1978): New formal approaches to the determination of energy and amino acid requirements of chicks. Poultry Science. 57. 1: 197-205.

Marcato, S. M.-Sakomura, N. K.-Munari, D. P.-Fernandes, J. B. K.-Kawauchi, I. M.- Bonato, M. A. (2008): Growth and body nutrient deposition of two broiler commercial genetic lines. Revista Brasileira de Ciência Avícola. 10. 2: 117-123.

National Research Council (1994): Nutrient requirements of poultry. $9^{\text {th }}$ revised edition. National Academy Press. Washington DC. USA.

Noblet, J. -Dubois, S. -Lasnier, J. -Warpechowski, M.-Dimon, P.Carré, B.-Labussière, E. (2015): Fasting heat production and metabolic BW in group-housed broilers. Animal. 9. 7: 11381144

Sakomura, N. K.-Fernandes, J. B. K.-Resende, K. T.-Rabello, C. B. V.-Longo, F.-Neme, R. (2011): Modelling energy utilization in poultry. Modelling nutrient digestion and utilisation in farm animals. Wageningen Academic Publishers. 297-305.

Sakomura, N. K.-Gous, R. M.-Marcato, S. M.-Fernandes, J. B. K. (2011): A description of the growth of the major body components of 2 broiler chicken strains. Poultry science. 90 . 12: $2888-2896$

Silva, E. P.-Sakomura, N. K.-Marcato, S. M.-Neme, R. (2014): 18. Description of the Growth of Body Components of Broilers and Laying Pullets. Nutritional Modelling for Pigs and Poultry. CABI. 250

Sütő, Z.-Horn, P.-Jensen, J. F.-Sørensen, P.-Csapo, J. (1998): Carcass traits, abdominal fat deposition and chemical composition of commercial meat type chicken during a twenty week growing period. Archiv fur Geflugelkunde. 62. 1: 21-25.

Tallentire, C. W.-Leinonen, I.-Kyriazakis, I. (2016): Breeding for efficiency in the broiler chicken: A review. Agronomy for Sustainable Development. 36. 4: 66

van Milgen, J.-Valancogne, A.-Dubois, S.-Dourmad, J. Y.-Sève, B.-Noblet, J. (2008): InraPorc: a model and decision support tool for the nutrition of growing pigs. Animal Feed Science and Technology. 143. 1: 387-405.

Zuidhof, M. J.-Schneider, B. L.-Carney, V. L.-Korver, D. R.Robinson, F. E. (2014): Growth, efficiency, and yield of commercial broilers from 1957, 1978, and 2005. Poultry Science. 93. 12: 2970-2982. 